\title{
Design of LED Lamp with special spectral characteristics
}

\author{
Petko Mashkov $^{1}$, Edmunds Teirumnieks ${ }^{2}$, Berkant Gyoch ${ }^{1}$, Hristo Beloev $^{1}$, \\ Tamara Pencheva ${ }^{1}$, Rostislav Kandilarov ${ }^{1}$ \\ ${ }^{1}$ University of Ruse. \\ Address: Studentska str. 8, Ruse, Bulgaria \\ ${ }^{2}$ Rezeknes Augstskola, Faculty of Engineering, \\ Environmental Technology Transfer Contactpoint. \\ Address: Atbrivosanas aleja 115, Rezekne, LV-4601, Latvia.
}

\begin{abstract}
The goal of this work is the design of LED lamp with adjustable spectral characteristics. The spectral power distribution (SPD) of the lamp can be adjusted to imitate the SPD of the daylight at noon and at evening. Noon light is "bluish" and stimulates cognitive abilities, work productivity and attention; sunlight at evening doesn't inhibit melatonin production leading to improved sleep during the night and better health. Special combinations of LEDs with different spectral and power characteristics and proper control of the LEDs' operation are used to achieve the required spectral characteristics of the lamp. Thermal management investigations are made at various ambient temperatures ranging from $20^{\circ} \mathrm{C}$ to $45^{\circ} \mathrm{C}$ and different current values through LEDs - up to their maximum values. They allow determining safety operating conditions for LEDs depending on the ambient conditions
\end{abstract}

Keywords: Power LEDs; LEDs' thermal management.

\section{INTRODUCTION}

In 2012 the Scientific Committee on Emerging and Newly Identified Health Risks (an independent scientific committee under the European Commission) published the report "Health Effects of Artificial Light". The report presented the possibilities for regulation of spectral characteristics of light sources to achieve better health, improved mood and work productivity. The interest in this topic has increased in the last couple of years. This is based on the possibilities to develop integrated energy efficient light sources which have variable spectral characteristics; can stimulate the cognitive abilities, work productivity and attention in factories and office buildings; change their light spectrum in the afternoon so it doesn't inhibit melatonin production leading to improved sleep during the night.

When the sun is high in the sky, the spectral composition of the light is more intensive in the blueviolet part of the spectrum (correlated colour temperature $\mathrm{CCT}=5500 \div 6500 \mathrm{~K}$ ). It is known [115] that the radiation in that part of the spectrum (with maximum close to $440 \mathrm{~nm}-480 \mathrm{~nm}$ ) stimulates the production of cortisol and improves the cognitive abilities, work productivity, concentration, focus, and has positive effect on the mood. On the other hand light in this part of the spectrum inhibits production of melatonin. Decrease in the production of this hormone leads to sleep problems and increases the risk of some cancers (breast cancer and others) [1-15].

During sunset sunlight passes through a thicker layer of air which leads to decrease of the intensity in the blue part of the spectrum and increase in the redorange part. Light of this kind of spectral composition doesn't inhibit melatonin production and the human body naturally prepares for rest and sleep.

The analysis of these facts leads to the conclusion that in order for artificial lightning to be beneficial for the health it needs to change its spectral composition in accordance with natural daylight.

The goals of this work are connected with design of LED lamp, proper for illumination a small room. The spectral characteristics of the lamp must be adjustable to imitate noon light $(\mathrm{CCT}=5500 \div 6500 \mathrm{~K})$ and sunlight at evening (CCT $\sim 3000 \mathrm{~K})$. The lamp's operation control has to be easy and cheap.

\section{MATERIALS AND METHODS}

Choice of LEDs with proper spectral and power characteristics

Meet specific design requirements of the lamp involves the use of LEDs with different spectral characteristics and different power. Our previous experience leads us to the use of LED module 
Samsung (COB), SPHWWTHDD 805WHV0ED [16] - Fig.1:

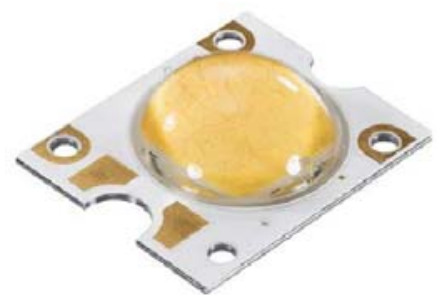

Fig. 1. Samsung LED, SPHWWTHDD 805WHV0ED [16].

Its light output is $800 \div 900 \mathrm{~lm}$ at $460 \mathrm{~mA}$ and 1012 $1 \mathrm{~m}$ at $620 \mathrm{~mA}$ (junction temperature $\mathrm{Tj}=25^{\circ} \mathrm{C}$ ) at CCT 3000K [16]. Its use allows the fulfillment of the requirements for night lighting with a luminous flux of about $800 \div 850 \mathrm{~lm}$.

To realize daylight with bluish light, which supports cognition, attention and working capacity is necessary to add LEDs with spectral characteristics with a maximum in the spectral region $440 \div 480 \mathrm{~nm}$. After analyzing the properties of LEDs with appropriate features our choice is - LEDs XLamp XPCBLU - CREE Inc. Spectral characteristics of this type of LEDs are shown in Fig.2.

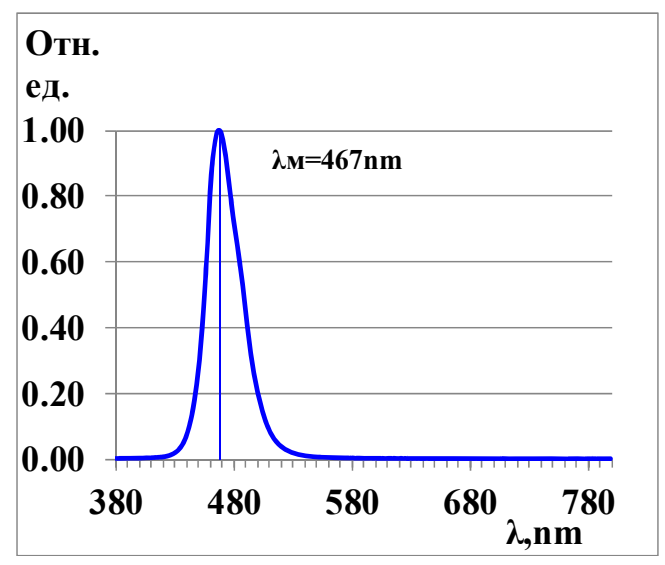

Fig. 2. Spectral characteristics of $X P C B L U$ - CREE Inc.

Using LEDs' chromaticity ( $\mathrm{x}, \mathrm{y}$ in the $1931 \mathrm{CIE}$ color space) and flux $(\Phi=\mathrm{Y})$ it is possible to calculate tristimulus values in color mixing, as follows [17]:

$$
\begin{gathered}
\mathrm{X}=\mathrm{x} *(\mathrm{Y} / \mathrm{y}) \\
\mathrm{Y}=\mathrm{Y} \\
\mathrm{Z}=(\mathrm{Y} / \mathrm{y}) *(1-\mathrm{x}-\mathrm{y}) . \\
\mathrm{Zmix}=\mathrm{Z} 1+\mathrm{Z} 2+\mathrm{Z} 3 \\
\mathrm{Xmix}=\mathrm{X} 1+\mathrm{X} 2+\mathrm{X} 3 \\
\mathrm{Ymix}=\mathrm{Y} 1+\mathrm{Y} 2+\mathrm{Y} 3 \\
\mathrm{X}_{\text {mix }}=\mathrm{Xmix} /(\mathrm{X} \text { mix }+\mathrm{Ymix}+\mathrm{Zmix}) \\
\mathrm{y}_{\text {mix }}=\mathrm{Ymix} /(\mathrm{Xmix}+\mathrm{Ymix}+\mathrm{Zmix}) \\
\Phi \operatorname{mix}=\mathrm{Y} 1+\mathrm{Y} 2+\mathrm{Y} 3
\end{gathered}
$$

For various combinations of LEDs using the relationships (1) to (3) allow spectral characteristics' evaluation of the resultant radiation and to select the most appropriate combination. Calculations showed that using only blue LEDs satisfy the requirement for a sufficient intensity in the blue area (needed to stimulate the production of cortisol), but the luminous flux of the lamp is not of good quality, as it is far from the Planck's locus.

Theoretical calculations have shown that the optimal use of two blue and three green LEDs plus LED module Samsung allows achieving design goals. In this combination and selection of the magnitude of the current through the LEDs may produce appropriate spectral characteristics of the lamp - the luminous flux about $800 \div 850 \mathrm{~lm}$ and the color temperature of $5500 \div 6000 \mathrm{~K}$. Green LEDs XLamp XPC - CREE Inc. are chosen.

All studies were further made in designed lamp are used: one LED module Samsung (Fig.1); two blue LEDs XPCBLU - CREE Inc. and three green LEDs XPCGRN -CREE Inc

\section{Thermal managements' calculations}

Usually for thermal managements calculations and junction temperature $\mathrm{Tj}$ estimations the thermal resistance model, described in [17], is used - Fig. 3.

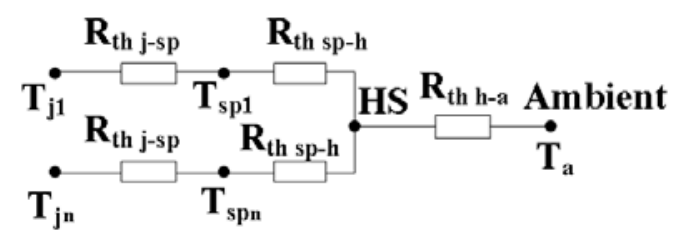

Fig. 3. Thermal resistance model for $n$ XLamps LEDs. $R_{\text {th }}$-sp thermal resistance from junction to solder point; $R_{\text {th sp- } h-\text { thermal }}$ resistance from solder point to heat sink; $\mathrm{R}_{\text {th h-a }}$ thermal resistance from heat sink to ambient; $\mathrm{T}_{\mathrm{j} 1}, \mathrm{~T}_{\mathrm{jn}}$ and $\mathrm{T}_{\mathrm{sp} 1}, \mathrm{~T}_{\mathrm{spn}}$ are junction and solder point temperatures corresponding.

$$
\mathrm{T}_{\text {jMAX }}=\mathrm{T}_{\mathrm{a}-\max }+\left(\mathrm{R}_{\text {thj-sp }}+\mathrm{R}_{\text {thsp-h }}\right) * \mathrm{P}_{\mathrm{LED}}+\mathrm{R}_{\text {thh-a }} * \mathrm{P}_{\text {tot }}
$$

where:

$\mathrm{R}_{\text {th h-a }}$ - thermal resistance from heat sink to ambient. $\mathrm{P}_{\mathrm{LED}}$ is the power of one LED chip:

$$
\mathrm{P}_{\mathrm{LED}}=\mathrm{I}_{\mathrm{F}} * \mathrm{U}_{\mathrm{F}} ;
$$

$\mathrm{P}_{\mathrm{LEDS}}=\mathrm{I}_{\mathrm{F}} * \mathrm{U}_{\mathrm{F}}=0.46 * 17=7.82 \mathrm{~W}$; for Samsung LED module;

$$
\mathrm{P}_{\mathrm{LEDBLU}}=\mathrm{I}_{\mathrm{F}} * \mathrm{U}_{\mathrm{F}}=0.35 * 3.3=1.16 \mathrm{~W} \text { for blue }
$$
LED;

$$
\mathrm{P}_{\mathrm{LEDGRN}}=\mathrm{I}_{\mathrm{F}} * \mathrm{U}_{\mathrm{F}}=0.35 * 3.4=1.19 \mathrm{~W} \text { for green }
$$
LED;

$\mathrm{P}_{\text {tot }}$ is the power of all LEDs:

$\mathrm{P}_{\text {tot }}=\mathrm{P}_{\text {LEDS }}+2 * \mathrm{P}_{\text {LEDBLU }}+3 * \mathrm{P}_{\text {LEDGRN }}=13.7 \mathrm{~W}$ 
For Samsung LED module $\mathrm{R}_{\mathrm{th} \text { j-sp }}=2.24^{\circ} \mathrm{C} / \mathrm{W} ; \mathrm{R}_{\mathrm{th}}$ sp-h $=0.4^{\circ} \mathrm{C} / \mathrm{W}[16]$;

For blue LED $\mathrm{R}_{\text {th } j \text {-sp }}=12^{\circ} \mathrm{C} / \mathrm{W}$; $\mathrm{R}_{\text {th sp-h }}=1{ }^{\circ} \mathrm{C} / \mathrm{W}$; [17].

For green LED $\mathrm{R}_{\text {th } \mathrm{j} \text {-sp }}=20^{\circ} \mathrm{C} / \mathrm{W} ; \mathrm{R}_{\text {th sp-h }}=1{ }^{\circ} \mathrm{C} / \mathrm{W}$

The calculations made on the basis of equation (4) show that heat sink with thermal resistance $\mathrm{R}_{\mathrm{th} \mathrm{h} \text {-a }}=$ $1^{\circ} \mathrm{C} / \mathrm{W}$ is sufficient - even under the most heavy operating conditions (ambient temperature $45^{\circ} \mathrm{C}$ and maximum operating current) junction temperature $T_{j}$ MAX of the LEDs does not exceed $85^{\circ} \mathrm{C}$ which is quite acceptable.

\section{RESULTS AND DISCUSSION}

\section{Spectral characteristics of the lamp}

Spectral characteristics are experimentally determined using measurements equipment of Stellar Net.

1. First operating regime - spectral power distribution (SPD) of the lamp stimulates cognitive abilities, work productivity, concentration, focus, and has positive effect on the mood.

In this case the spectral distribution of the radiation is characterized by a peak in the area $440 \div 480 \mathrm{~nm}$. All LEDs are on, the size of the current through the blue and green LEDs is $350 \mathrm{~mA}$; by controlling the magnitude of the current through Samsung LED module correlated color temperature can be set between $5000 \mathrm{~K}$ and $6000 \mathrm{~K}$ - Fig. 5 - Fig. 8 .

Depending on the selected mode of operation and ambient temperature the luminous flux is in the interval $800 \div 850 \mathrm{~lm}$. As can be seen from Fig. 5, Fig. 7 and Fig. 8 the coordinates of the radiant flux is positioned close to the Plank's locus.

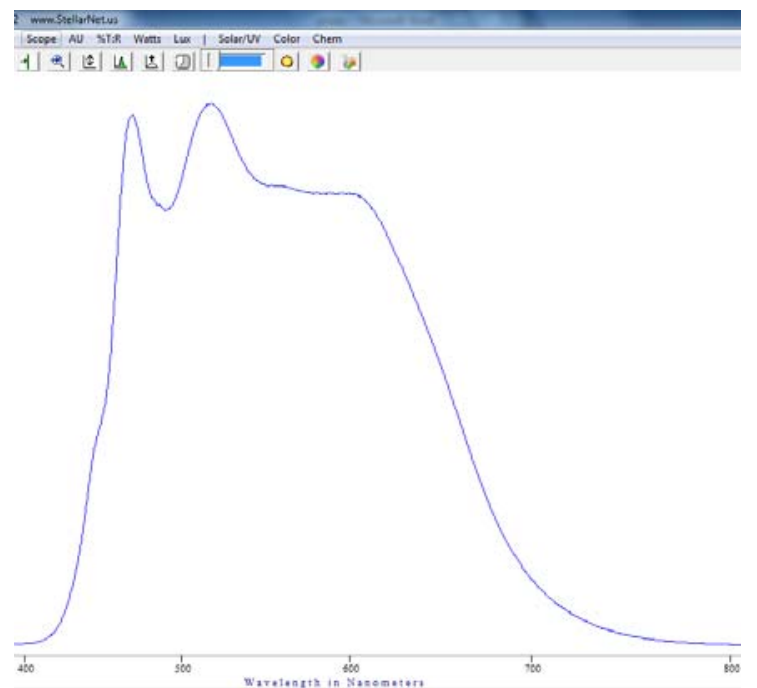

Fig. 4. Lamp's spectral characteristic. The current through the blue and green LEDs is $350 \mathrm{~mA}$; through Samsung LED module $360 \mathrm{~mA}$.

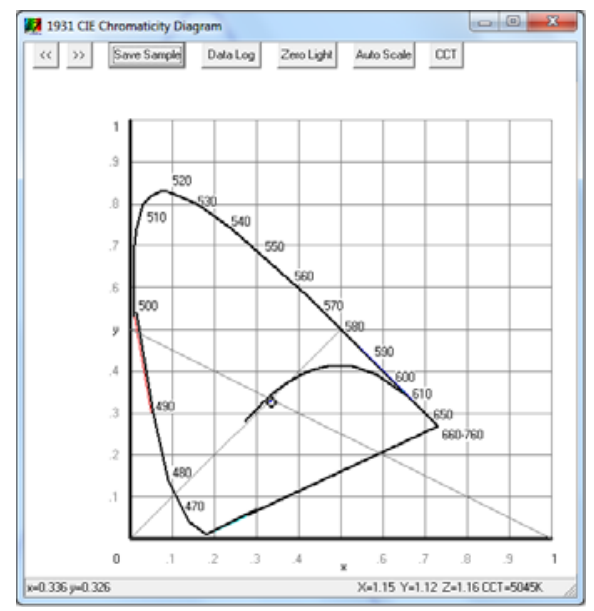

Fig. 5. Color temperature 5045K.

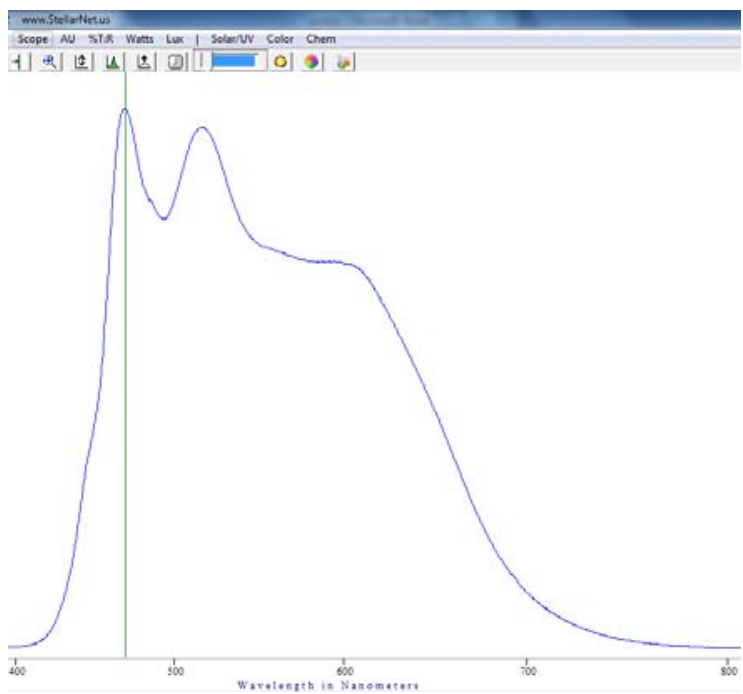

Fig. 6. Lamp's spectral characteristic. The current through the blue and green LEDs is $350 \mathrm{~mA}$; through Samsung LED module $300 \mathrm{~mA}$.

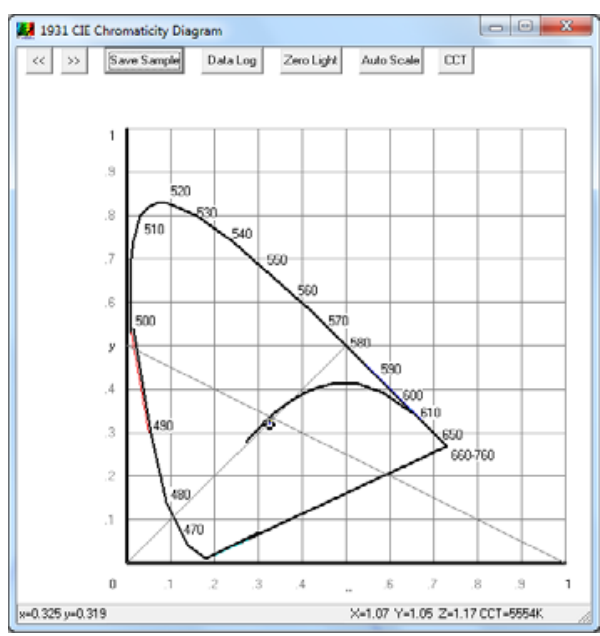

Fig. 7. Color temperature 5554K. 


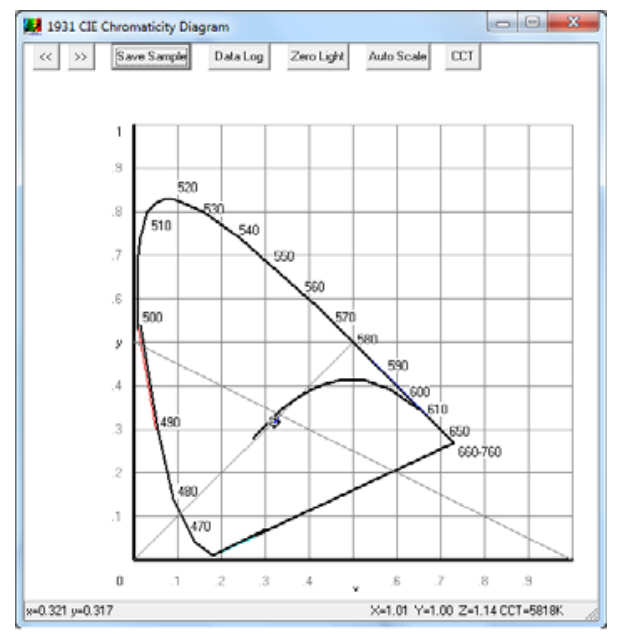

Fig. 8. Color temperature 5818K.

2. Lamp's spectral power distribution (SPD) which doesn't inhibit melatonin production and the human body naturally prepares for rest and sleep.

In this case only lights the Samsung LED module. To maintain the same luminous flux $(800 \div 850 \mathrm{~lm})$ the current through the LED module is increased up to $500 \mathrm{~mA}$. In the spectral distribution of the light flux is absent intense blue component, which suppresses the production of melatonin - Fig. 9. The CCT of the luminous flux is about $3000 \mathrm{~K}-$ Fig. 10. These features in the spectral distribution of the lamp's luminous flux makes it suitable for lighting in the second half of the day - late afternoon and evening, when the human body naturally prepares for rest and sleep.

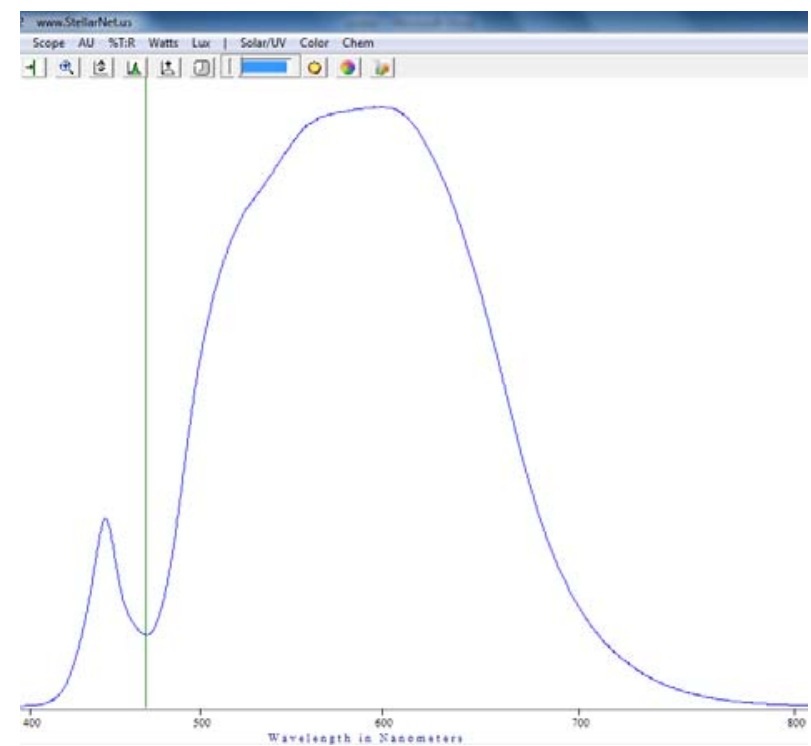

Fig. 9. Lamp's spectral characteristic. The current through the Samsung LED module is $500 \mathrm{~mA}$.

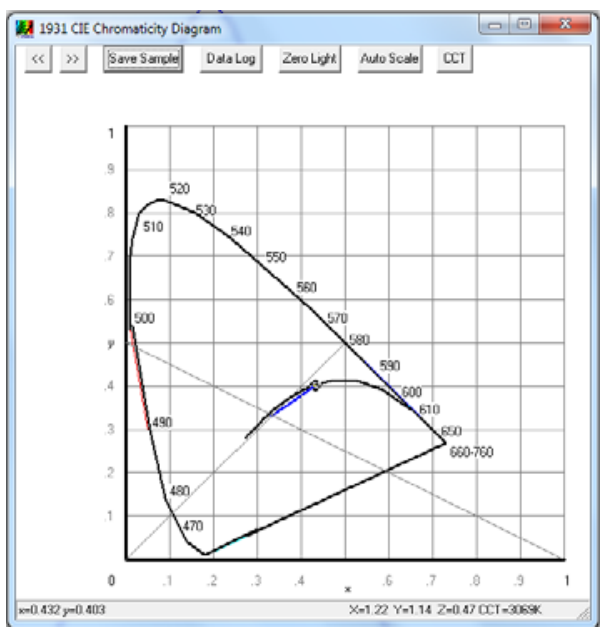

Fig. 10. Color temperature 3069K.

\section{LEDs' thermal management. Experimental investigations.}

Experiments are made in a thermal chamber where the temperature is kept at desirable values with the accuracy better than $0.5^{\circ} \mathrm{C}$.

Solder point temperatures' distributions are measured using IR camera Therma Cam E300 - FLIR Systems; results are verified using standard measurement technique - by thermocouples.

At each value of solder points' temperatures $\mathrm{T}_{\mathrm{sp}}$ the corresponding temperatures of the LEDs' junction are calculated in accordance with [17]:

$$
\mathrm{T}_{\mathrm{j}}=\mathrm{T}_{\mathrm{sp}}+\mathrm{R}_{\mathrm{th} \mathrm{j} \text {-sp }} * \mathrm{P}_{\mathrm{LED}} .
$$

Results are presented below:

1. First regime of operation - all LEDs are switched on; the currents' values through LEDs are: for Samsung module $I_{\text {Samsung }}=460 \mathrm{~mA}$; for green and blue LEDs $I_{G R N}=I_{B L U}=350 \mathrm{~mA}$.

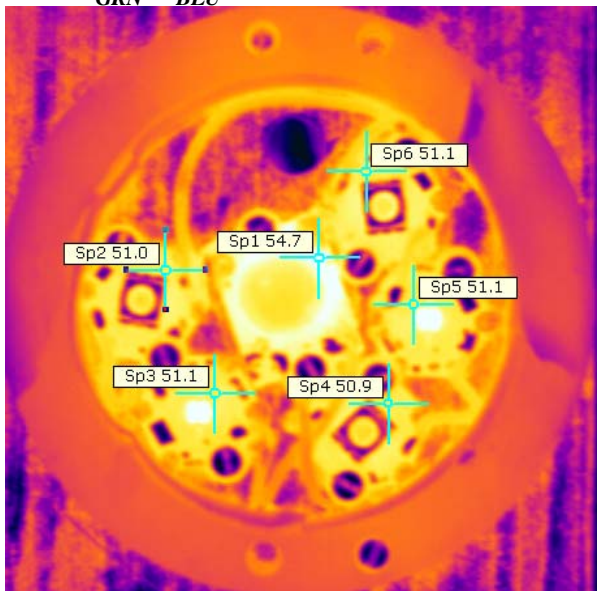

Fig. 11a. First regime of operation. IR photo of LED lamp. Sp measured solder point temperatures. Ambient temperature $\mathrm{Ta}=25^{\circ} \mathrm{C}$. 


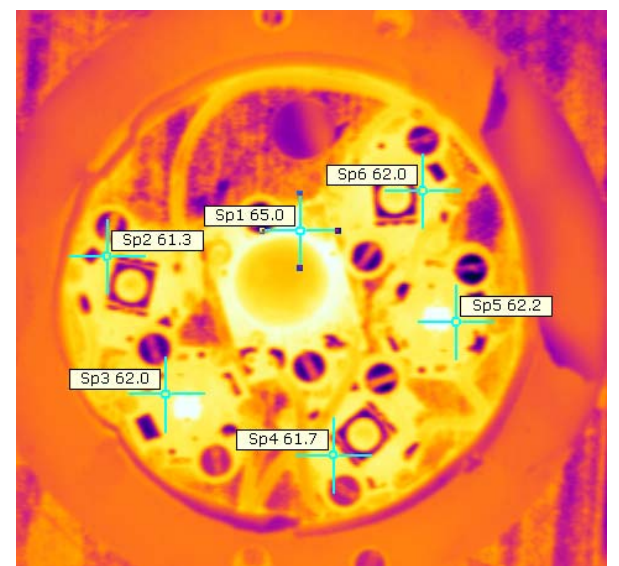

Fig. 11b. First regime of operation. IR photo of LED lamp $\mathrm{Sp}$ - measured solder point temperatures. Ambient temperature $\mathrm{Ta}=45^{\circ} \mathrm{C}$.

In Fig. $12 \div$ Fig. 14 measured temperatures of solder points of LEDs and corresponding calculated junctions' temperatures at different temperatures of ambient air are presented.

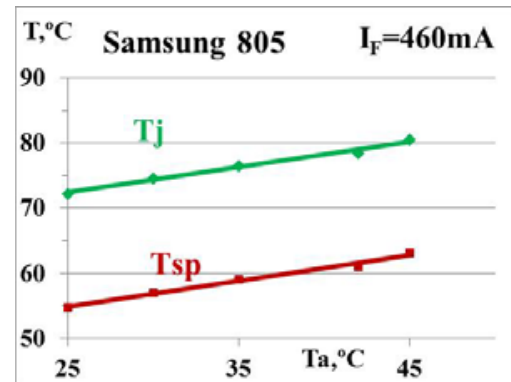

Fig. 12. Solder point's temperature $\mathrm{T}_{\mathrm{sp}}$ and junction temperature $T_{j}$ dependences on temperature of the ambient air $T_{a}$ for the Samsung module;

$\mathrm{I}_{\mathrm{F}}=460 \mathrm{~mA}-$ forward current through Samsung module.

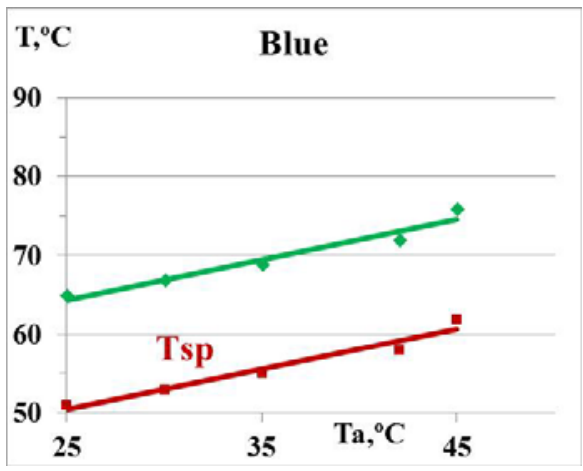

Fig. 13. Solder point's temperature $\mathrm{T}_{\mathrm{sp}}$ and junction temperature $T_{j}$ dependences on temperature of the ambient air $T_{a}$ for the blue LEDs; $\mathrm{I}_{\mathrm{F}}=350 \mathrm{~mA}$ - forward current through blue LEDs.

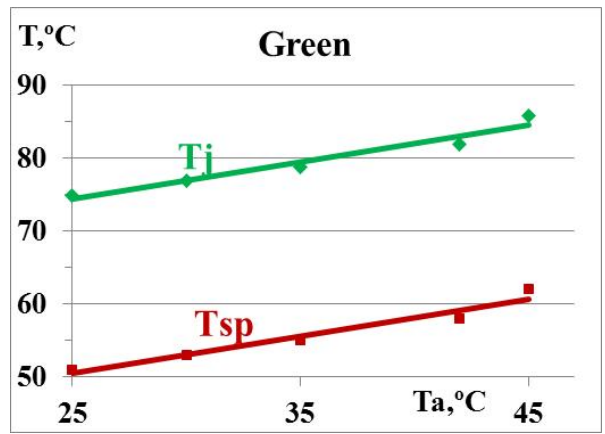

Fig. 14. Solder point's temperature $\mathrm{T}_{\mathrm{sp}}$ and junction temperature $T_{j}$ dependences on temperature of the ambient air $T_{a}$ for the green LEDs; $\mathrm{I}_{\mathrm{F}}=350 \mathrm{~mA}$ - forward current through green LEDs.

\section{Second regime of operation - only Samsung} LED module is switched on; the current through Samsung LED module is $I_{\text {Samsung }}=500 \mathrm{~mA}$.

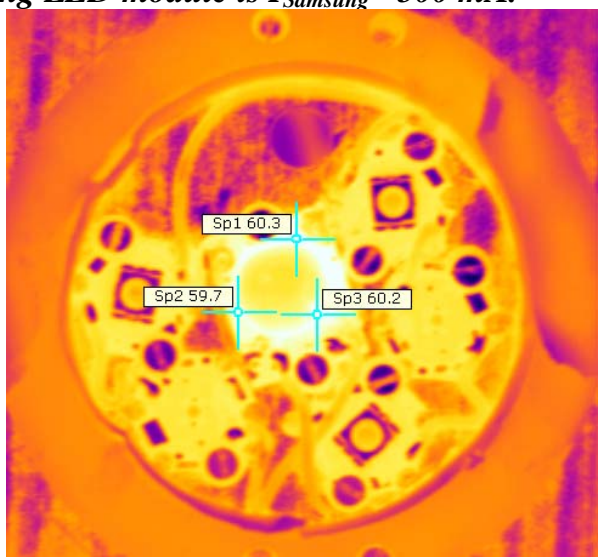

Fig. 15. Second regime of operation. IR photo of LED lamp. $\mathrm{Sp}-$ measured solder point temperatures. Ambient temperature $\mathrm{Ta}=42^{\circ} \mathrm{C}$

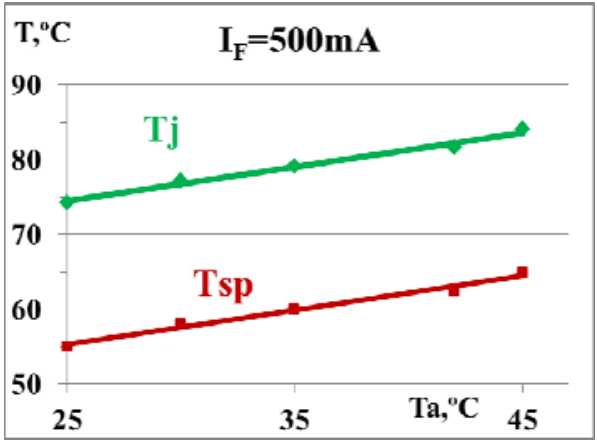

Fig. 16. Second regime of operation. Solder point's temperature $T_{s p}$ and junction temperature $T_{j}$ dependences on temperature of the ambient air $\mathrm{T}_{\mathrm{a}}$ for the Samsung module; $\mathrm{I}_{\mathrm{F}}=500 \mathrm{~mA}$ - forward current through Samsung module.

As it can be seen from the Fig. 12, Fig. 13, Fig. 14 and Fig. 16 junction temperatures $\mathrm{T}_{\mathrm{j}}$ for all types of LEDs don't exceed $85^{\circ} \mathrm{C}$, which ensure safety working condition and long life of the designed lighting equipment. 


\section{CONCLUSION}

LED lamp with special spectral characteristics is designed and produced. The spectral characteristics of the lamp contribute to the preservation of human health. The lamp can be used in two modes of operation: in the first mode (lighting during the day) spectral characteristics of the light stimulate the production of cortisol (and inhibits production of melatonin) in the human body and improves the cognitive abilities, work productivity, concentration, focus, and has positive effect on the mood; in the second regime (lighting in the evening) light's spectral characteristics doesn't inhibit melatonin production and the human body naturally prepares for rest and sleep. The transition between the two modes of operation can be performed quite simply - with a key or remote control.

\section{$\mathrm{V}$ ACKNOWLEDGMENTS}

The National Science Fund, Ministry of Education and Science of Bulgaria, is gratefully acknowledged for the financial support of research project DFNI B02/2 12.12.2014 (Int. № FNI B 02/75).

\section{REFERENCES}

[1] B. Ramos-Alvarado, B. Feng, G.P. Peterson, Comparison and optimization of single-phase liquid cooling devices for the heat dissipation of high-power LED arrays, Applied Thermal Engineering, 59, (2013), pp. 648-659

[2] 20. Bellia L. , A. Pedace, G. Barbato, Lighting in educational environments: An example of a complete analysis of the effects of daylight and electric light on occupants, Building and Environment, 68 (2013), pp. 50-65.

[3] Cajochen C. , Alerting effects of light, Sleep Medicine Reviews (2007)11, pp.453-464.

[4] Chellappa L. S., R. Steiner, P. Blattner, P. Oelhafen, T.Gotz, C. Cajochen, Non-Visual Effects of Light on Melatonin, Alertness and Cognitive Performance: Can Blue-Enriched
Light Keep Us Alert?, Blue-Enriched Light, Alertness and Performance, January 2011 , Volume 6 , Issue 1 , e16429, pp.1-12.

[5] Edwards L.and P. Torcellini, A Literature Review of the Effects of Natural Light on Building Occupants, U.S. Department of Energy Laboratory, 2002, p.58.

[6] Ellis E. V. , E. W. Gonzalez, D. A. Kratzer, D. L. McEachron, G. Yeutter, Auto-tuning Daylight with LEDs: Sustainable Lighting for Health and Wellbeing, ARCC 2013, The Visibility of Research Sustainability: Visualization Sustainability and Performance, pp.465-473.

[7] Fisk W. J. , Review of Health and Productivity Gains From Better IEQ, Proceedings of Healthy Buildings 2000, vol 4, pp 23-34.

[8] Gabel V. , M. Maire, C. F. Reichert, S. L. Chellappa, C. Schmidt,V. Hommes, A. U. Viola and C. Cajochen, Effects of Artificial Dawn and Morning Blue Light on Daytime Cognitive Performance, Well-being, Cortisol and Melatonin Levels, Chronobiology International, Informa Healthcare USA, Inc (2013), pp.1-10.

[9] Illuminating the Effects of Dynamic Lighting on Student Learning, Michael S. Mott - The University of Mississippi, Daniel H. Robinson -The University of Texas, Ashley Walden, Jodie Burnette \& Angela S. Rutherford - The University of Mississippi

[10] In-Tae Kim, An-Seop Choi, Jae-Weon Jeong, Precise control of a correlated color temperature tunable luminaire for a suitable luminous environment, Building and Environment, 57 (2012), pp. 302-312.

[11] Ir.W. J. M. van Bommel and Ir. G. J. van den Beld, Lighting for work: visual and biological effects, April 2004, Philips Lighting, The Netherlands, 2004, p.20.

[12] Ir.W.J.M. van Bommel, Ir. G.J. van den Beld, Ir. M.H.F. van Ooijen. Industrial lighting and productivity, Philips Lighting, The Netherlands, 2002, p. 20.

[13] Joseph A., The Impact of Light on Outcomes in Healthcare Settings, 2006 The Center for Health Design, p.14.

[14] Knez I. Effects of colour of light on nonvisual psychological processes, Journal of Environmental Psychology, Volume 21, Issue 2, June 2001, pp. 201-208.

[15] L. Bellia, F. Bisegna, G. Spada, Lighting in indoor environments: Visual and non-visual effects of light sources with different spectral power distributions, Building and Environment, 46, (2011), pp. 1984-1992.

[16] www.samsung.com

[17] www.cree.com/xlamp 